\title{
The effect of oral sildenafil therapy on health-related quality of life in adults with pulmonary arterial hypertension related to uncorrected secundum atrial septal defect: a quasi experimental study
}

Fera Hidayati ${ }^{*}$ (1), Putrika P. R. Gharini, Anggoro Budi Hartopo, Dyah Wulan Anggrahini and Lucia Kris Dinarti

\begin{abstract}
Background: Assessment of health-related quality of life (HRQOL) are often measured as an important patientreported outcome (PRO) in clinical studies. Pulmonary arterial hypertension (PAH) is a common complication of atrial septal defect (ASD). This study aimed to compare the HRQoL of PAH related uncorrected secundum ASD at pre and post therapy with oral sildenafil therapy.

Methods: We conducted quasi experimental study at Sardjito General Hospital Yogyakarta since April 2016 to August 2017. Adults with PAH related uncorrected secundum ASD, listed on Congenital Heart Disease and Pulmonary Hypertension (COHARD-PH) registry, and met the inclusion and exclusion criteria were recruited as subject. Interview was done at pre and 12 weeks post oral sildenafil therapy $3 \times 20 \mathrm{mg}$ using the EQ-5D-3L questionnaire. Statistical analysis was done using Wilcoxon test and paired T-test to determine the differences of EQ-5D utility and EQ-VAS score at pre and post therapy.

Results: A total of 18 adult patients with PAH related to uncorrected secundum ASD were enrolled in this study (83.33\% female; mean age $38.72 \pm 10.81$ years old). The most frequent reported problems pre therapy were pain/ discomfort (83\%) and anxiety/depression (78\%). Wilcoxon test showed the median of EQ-5D utility score were increased after sildenafil therapy (before $=0.604$, after $=0.664 ; Z=-2703 ; p: 0.007$ ), respectively. Meanwhile, the paired T-test results showed an increase of EQ-VAS mean difference $6.67 \pm 8.75$ (p:0.005; 95\% Cl 2.32-11.02) after sildenafil therapy.
\end{abstract}

Conclusion: The administration of oral sildenafil therapy $3 \times 20$ mg during 12 weeks in adult patients with PAH related uncorrected secundum ASD gives better HRQOL.

Keywords: Health-related quality of life, Pulmonary arterial hypertension, Atrial septal defect, Sildenafil

\footnotetext{
* Correspondence: fera.hidayati@gmail.com

Cardiology and Vascular Department, Faculty of Medicine, Public Health and Nursing, Universitas Gadjah Mada - Dr. Sardjito Hospital, Yogyakarta, Indonesia
}

(c) The Author(s). 2020 Open Access This article is licensed under a Creative Commons Attribution 4.0 International License, which permits use, sharing, adaptation, distribution and reproduction in any medium or format, as long as you give appropriate credit to the original author(s) and the source, provide a link to the Creative Commons licence, and indicate if changes were made. The images or other third party material in this article are included in the article's Creative Commons licence, unless indicated otherwise in a credit line to the material. If material is not included in the article's Creative Commons licence and your intended use is not permitted by statutory regulation or exceeds the permitted use, you will need to obtain permission directly from the copyright holder. To view a copy of this licence, visit http://creativecommons.org/licenses/by/4.0/. The Creative Commons Public Domain Dedication waiver (http://creativecommons.org/publicdomain/zero/1.0/) applies to the data made available in this article, unless otherwise stated in a credit line to the data. 


\section{Backgrounds}

Pulmonary Artery Hypertension (PAH) is a common complication of congenital heart disease which mostly happen on patients with left to right shunt, such as atrial septal defect (ASD). Uncorrected left to right shunt may increase pulmonary pressure and lead to vascular remodeling and dysfunction. Thus, it is responsible for progressive increase of pulmonary vascular resistance and right heart pressure [1]. Based on disease registry of PAH on ASD patients in Sardjito General Hospital Yogyakarta, out of 123 adult ASD patients, 74\% among them had PAH [2]. Post (2013) mentioned that PAH was found in $9-35 \%$ secundum ASD, including those who have or have not corrected [3].

PAH symptoms such as activity-induced dyspnea, dizziness, cough, chest pain, palpitation, and peripheral edema may impact the physical mobility and emotional status that could worsen the patients' health related quality of life (HRQoL) [4]. HRQoL is a parameter of personal satisfaction in living affected by health status, such as physical capacity, cognitive ability, working relations, emotional and spirituality. It is subjective, multidimensional, and temporary [5]. To date, only few data showed a potential output from patient-reported outcome (PRO) in showing the prognosis of PAH. PRO is a patient's health parameter measured by themselves which includes HRQoL, that is a functional effect of disease and therapy consequences by patient's judgement [6].

Meta-analysis of 4 researches on safety and efficacy of sildenafil therapy for $>12$ weeks in patients with PAH concludes that sildenafil significantly decrease clinical deterioration events and increase 6 min' walk test distance, WHO functional class, hemodynamic parameters and HRQoL compared to placebo [7]. HRQoL improvement has been reported in PAH patients with the specific therapy, but it does not show consistency in all of the researches [8-11]. Thus, we aim to investigate whether there are HRQoL differences before and after sildenafil therapy in adult patients with $\mathrm{PAH}$ related uncorrected secundum ASD.

There are many disease-specific questionnaires for PAH such as Cambridge Pulmonary Hypertension Outcome Review (CAMPHOR), emPHasis-10, Minnesota Living with Heart Failure Questionnaire (MLHFQ), Pulmonary Arterial Hypertension Symptom Scale (PAHSS), and Living with Pulmonary Hypertension (LPH) [12]. However, we use EQ-5D-3L questionnaire as a tool to assess HRQoL because its serve the aim of selfcompletion, only need a few minutes to complete, has a value set which can be used to evaluate quality-adjusted life-years (QALY), and we obtain freely access to this questionnaire from EuroQol [13]. The EQ-5D-3L questionnaire also has been proven to be valid and reliable in Indonesian population [14].

\section{Methods}

Study design

We conducted a quasi-experimental research in Sardjito General Hospital Yogyakarta from April 2016 to August 2017. The subject included in this research was adult patients (age $\geq 18$ years) with $\mathrm{PAH}$ and uncorrected secundum ASD who had been registered on COHARD-PH registry and signed the informed consent. Secundum ASD was diagnosed by trans thoracic echocardiography and trans esophageal echocardiography, meanwhile PAH was diagnosed by right heart catheterization. Exclusion criteria were not completing 12-weeks follow up, other congenital heart defect, WHO NYHA functional class I, had received specific therapy for PAH, pregnancy, had received nitrates, or chronic pulmonary diseases.

Demography and clinical data; such as age, gender, WHO functional class, marital status, comorbid disease, and other therapy; were recorded in case report form. Subject filled HRQoL questionnaire before and 12 weeks after receiving oral sildenafil $3 \times 20 \mathrm{mg}$. The therapy adherence was done by multiple phone call reminder and two-weeks-routine follow up to the hospital. Side effect evaluation and dose adjustment toward the clinical condition were done in every routine follow-up meeting.

Instrument to measure HRQoL was generic questionnaire EuroQol-5 Dimensions 3 Levels (EQ-5D-3L) which had been proven validity and reliability. This questionnaire was developed by the EuroQol Group which consist of 2 parts; EQ-5D descriptive system and visual analogue scale (EQ-VAS).

The descriptive system assesses patients' quality of life in 5 dimensions which are mobility, self-care, usual activities, pain/discomfort, and anxiety/depression. Based on the response level in each EQ-5D-3L dimension, subjects will be categorized into no-problem group, moderate-problem group, and severe-problem group.

The response of each dimension in the EQ-5D descriptive system will be converted into single summary index based on valuation techniques that will create a value set for each level in the index. The values are adjusted differently in various countries and related to a health state [13]. The index ranged between 0 and 1 [15]. A value of 0 is equivalent to being dead while a value of 1 means the healthiest condition imaginable. The Malaysia value set was used in this research. The valuation technique used to estimate the Malaysia EQ-5D value set was Time Tradeoff (TTO) and Visual Analogue Scale (VAS) [16]. To date, there are no value set of EQ-5D-3L available for Indonesia. Endarti (2016) stated that Malaysia value set is preferable to use in Indonesian population compared to another value set [17].

The EQ-VAS is a self-rated measurement which concerned to imaginable health state by subject with score range $0-100$ [13]. 
The difference of EQ-5D utility score and EQ-VAS before and after therapy will be analyzed further.

\section{Sample size}

Using the formula to determine minimum sample for numerical analysis research and considering the 10\% drop-out rate, we found that estimated sample needed was 19 subjects. The 'standard deviation of the mean' and ' $\mathrm{x}_{1}-\mathrm{x}_{2}$ ' value was adapted from the research conducted by Peppe-Zaba [8].

\section{Echocardiography evaluation}

Trans thoracic echocardiography was performed by experienced technician and verified by cardiologist consultants. Bubble test was performed when interatrial defect was not clear on echocardiography examination. Bubble test and trans esophageal echocardiography was conducted by cardiologist consultant.

\section{Right cardiac catheterization}

Right cardiac catheterization was performed by a cardiologist through standard operating procedure in Sardjito General Hospital Yogyakarta, using angiography machine Xper Cardio Physiomonitoring 5 hemodynamic monitors (Philips, USA). Saturation and pressure were measured on every location using oximeter (Avoximeter ${ }^{\circ}$ 1000E, USA).

\section{Questionnaire EQ-5D-3L data sampling}

Questionnaire data sampling was performed by trained enumerator. Data sampling was performed through (1) Subject was given a thorough explanation about the questionnaire filling, (2) Subject filled the questionnaire, (3) Subject was allowed to ask questions, (4) Subject could be assisted on reading and filling questionnaire, if needed.

\section{Statistical analysis}

Statistical analysis was performed using SPSS for Windows 22.0. Continuous variables are presented as mean \pm standard deviation, while categorical variables are presented as percentages. Comparative analysis for paired categorical variables (before and after therapy) was performed for every EQ-5D dimension using McNemar and Wilcoxon test. Comparative analysis to compare the EQ-5D utility score and EQ-VAS before and after therapy was performed using Wilcoxon signed rank test and paired T-test, respectively. Consequent analysis was performed to find the correlation between factors that influence difference between utility score of EQ. 5D and EQVAS. The analysis was performed using Mann Whitney test due to abnormal data distribution. $p$ value $<0,05$ was considered statistically significant.

\section{Results}

A total of 22 patients were included in the study subjects. During the study, 4 subjects were dropped out (one subject died in a local hospital about a week after starting sildenafil therapy, two subjects did not continue the study at the 4th week due to loss of follow up, and one subject only followed the study until the 8th week because of health insurance issues) and were not analyzed further. We could not determine the patient's cause of death because she died in another hospital. But, based on the follow up by phone call that the patients felt shortness of breath, we assumed that the cause of death was related to the PAH complication rather than the sildenafil effect. We obtained 18 patients who could follow the study for 12 weeks. During the study, there were 2 subjects $(11.11 \%)$ who reported dizziness after taking sildenafil $3 \times 20 \mathrm{mg}$. Because of that, the sildenafil dose was reduced to $2 \times 20 \mathrm{mg}$ and the dizziness improved. This is considered a mild side effect which improved after dose reduction.

Subjects were predominantly women with $83.33 \%$ (15) subjects being women. Mean age of subjects was $38.72 \pm 10.81$ years old. All of the subjects were symptomatic, $72.22 \%$ (13) subjects were in WHO functional class II and $27.78 \%$ (5) were in WHO functional class III. The majority of subjects were married (83.33\%), 3 of whom had no children and 2 were widowed. 11 (61.11\%) subjects were housewives.

Other comorbid diseases were present in 2 subjects (11.11\%) with one subject diagnosed with atrial fibrillation and one subject diagnosed with ischemic heart disease, whereas 16 subjects (88.89\%) were not accompanied by other diseases. A total of 10 subjects (55.56\%) did not receive supportive PAH therapy (furosemide, digoxin, spironolactone, warfarin) and 8 subjects $(44.44 \%)$ treated with supportive PAH therapy. Table 1 showed basic characteristics of $\mathrm{PAH}$ subjects with uncorrected ASD II who received sildenafil $3 \times 20$ mg for 12 weeks.

The subjects were further categorized into three groups; which were no-problem group, moderateproblem group, and severe-problem group at the time before and after sildenafil therapy based on the response level of EQ-5D-3L questionnaire. Figure 1 showed that the most reported problems were pain/discomfort $(72 \%$ moderate and $11 \%$ severe problems), followed by anxiety/ depression (67\% moderate and $11 \%$ severe problems), and usual activities limitations (33\% moderate problems and $6 \%$ severe problems). After receiving $3 \times$ $20 \mathrm{mg}$ sildenafil therapy for 12 weeks, those severe problems were no longer reported by the subject.

Figures 2 and 3 showed the difference of EQ-5D utility set and EQ-VAS before and after sildenafil therapy. Comparative analysis before and after therapy was 
Table 1 Baseline characteristic of subject

\begin{tabular}{|c|c|c|}
\hline Variable & & Value $(\boldsymbol{n}=18)$ \\
\hline Age (years) & Mean \pm SD & $38.72 \pm 10.81$ \\
\hline \multirow[t]{2}{*}{ Gender } & Female, n (\%) & $15(83.33)$ \\
\hline & Male, n (\%) & $3(16.67)$ \\
\hline \multirow[t]{2}{*}{ WHO Functional Class } & II, n (\%) & $13(72.22)$ \\
\hline & III, n (\%) & $5(27.78)$ \\
\hline \multirow[t]{4}{*}{ Marital Status } & Not married, n (\%) & $3(16.67)$ \\
\hline & Married, with children, n (\%) & $10(55.56)$ \\
\hline & Married, no children, n (\%) & $3(16.67)$ \\
\hline & Widowed, n (\%) & $2(11.11)$ \\
\hline \multirow[t]{5}{*}{ Occupation } & Housewives, n (\%) & $11(61.11)$ \\
\hline & Civil servant, n (\%) & $2(11.11)$ \\
\hline & Private employee, n (\%) & $3(16.67)$ \\
\hline & College student, n (\%) & $1(5.56)$ \\
\hline & Unemployed, n (\%) & $1(5.56)$ \\
\hline \multirow[t]{2}{*}{ Comorbid disease } & None, n (\%) & $16(88.89)$ \\
\hline & Present, n (\%) & $2(11.11)$ \\
\hline \multirow[t]{6}{*}{ Other therapy } & No therapy, n (\%) & $10(55.56)$ \\
\hline & Furosemide, n (\%) & $8(44.44)$ \\
\hline & Digoxin, n (\%) & $7(38.89)$ \\
\hline & Spironolactone, n (\%) & $1(5.56)$ \\
\hline & Warfarin, n (\%) & $1(5.56)$ \\
\hline & Aspirin, n (\%) & $1(5.56)$ \\
\hline
\end{tabular}

SD Standard Deviation performed using Wilcoxon test for EQ-5D utility score and paired $\mathrm{T}$ test for EQ-VAS. The result was shown in Table 2. The median of EQ-5D utility score were increased after therapy (before $=0.604$, after $=0.664 ; \mathrm{Z}=-$ 2.703, p:0,007), while the mean of EQ-VAS score also were increased $6.67 \pm 8.75$ (95\% CI, 2.32 to 11.02$) p$ value 0.005 .

Thus, there were statistically significant result in both median difference of EQ-5D utility score and mean difference of EQ-VAS before and 12 weeks after oral sildenafil therapy.

The subjects studied were the same subjects who performed HRQoL measurements twice, before and after therapy. Factors influencing changes in EQ-5D and EQVAS utility scores were analyzed by re-grouping subjects based on these factors, such as sex group (male and female), age ( $>38$ years and $\leq 38$ years), education level (low and high), marital status (married and not married), employment status (employed and unemployed), other therapies (with and without other therapies), and comorbidities (with and without coexisting illness).

There was an increase of EQ-5D and EQ-VAS utility score after oral sildenafil therapy in all of the sub groups. The EQ-5D and EQ-VAS utility score differences were calculated in each sub-group and were analyzed using Mann Whitney test due to abnormal data distribution. $p$ value $<0.05$ is considered statistically significant. From Table 3, there was no statistically significant difference between all factors affecting HRQoL to the difference of EQ-5D and EQ-VAS utility scores.

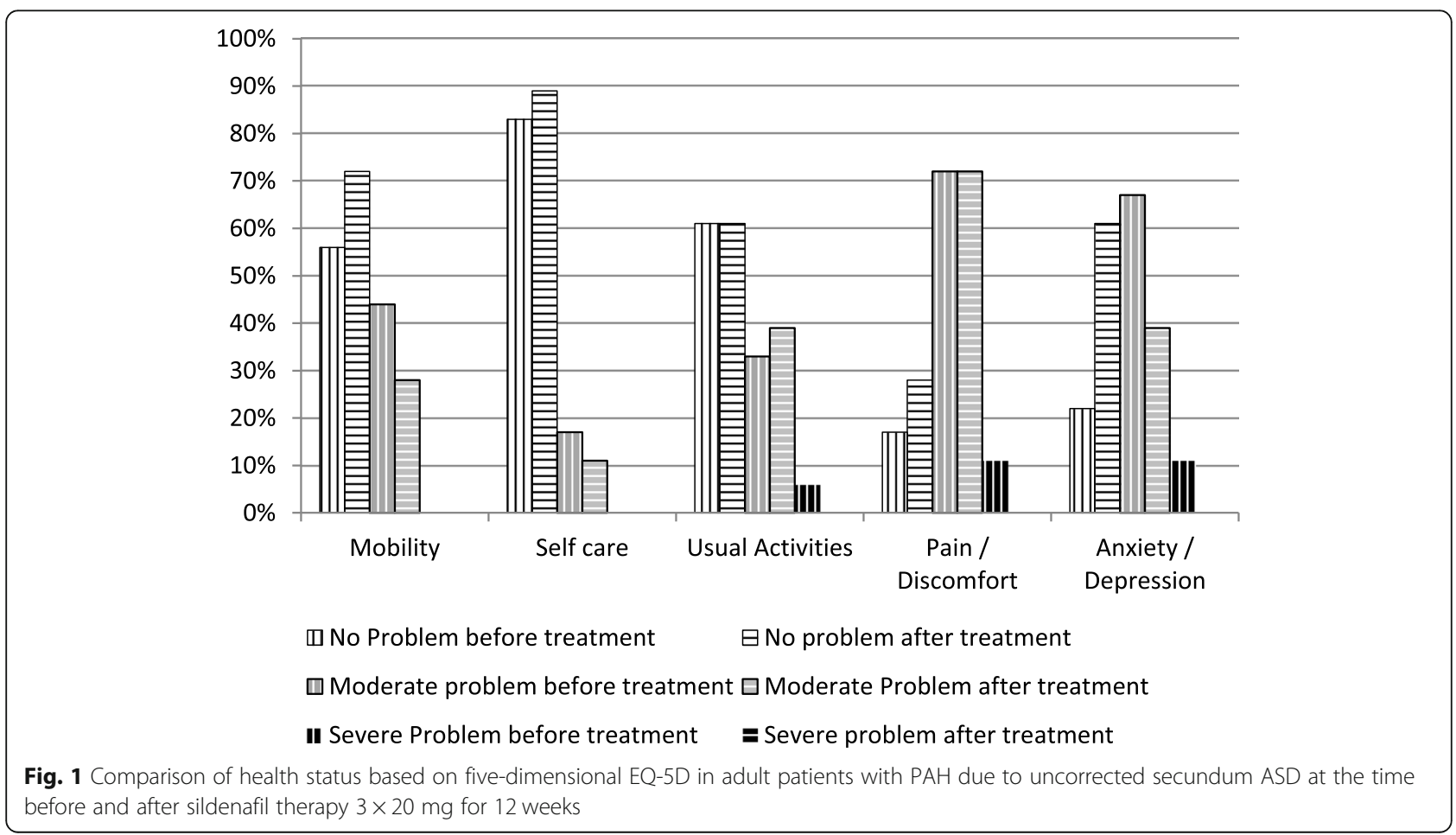




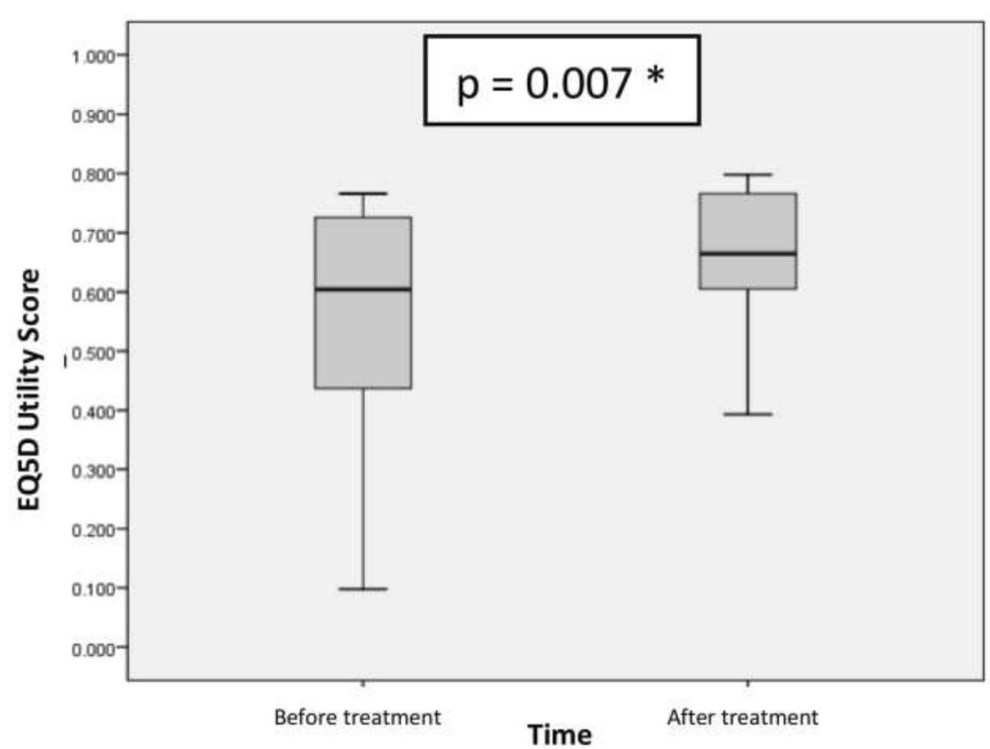

Fig. 2 The median of EQ-5D utility score before and after 12 weeks of oral sildenafil therapy $3 \times 20 \mathrm{mg}$ in adult patients with PAH due to uncorrected secundum ASD proved to be statistically significant. * $p<0.05$

\section{Discussion}

Based on the data, we found that the mean age of subjects diagnosed as $\mathrm{PAH}$ in uncorrected secundum ASD was 38.72 years. These results are in accordance with the study of Haque et al. (2015) which stated that PAH development in secundum ASD mostly occurred in the third decade [18]. Vogel et al. (1999) noted that the incidence of PAH in secundum ASD were increased in patients at the age of 18 to 40 year old [19]. The majority of the subjects of this study were female (83.33\%) which similar to the previous study [19]. Euro Heart Survey registry also support this findings. They concluded that the incidence of PAH in female ASD was $76.6 \%$, higher than male patients [20].

All subjects have many problems in various EQ-5D dimensions before starting the specific PAH therapy. In general, subjects reported their best performance on the self-care dimension and their worst on pain/discomfort

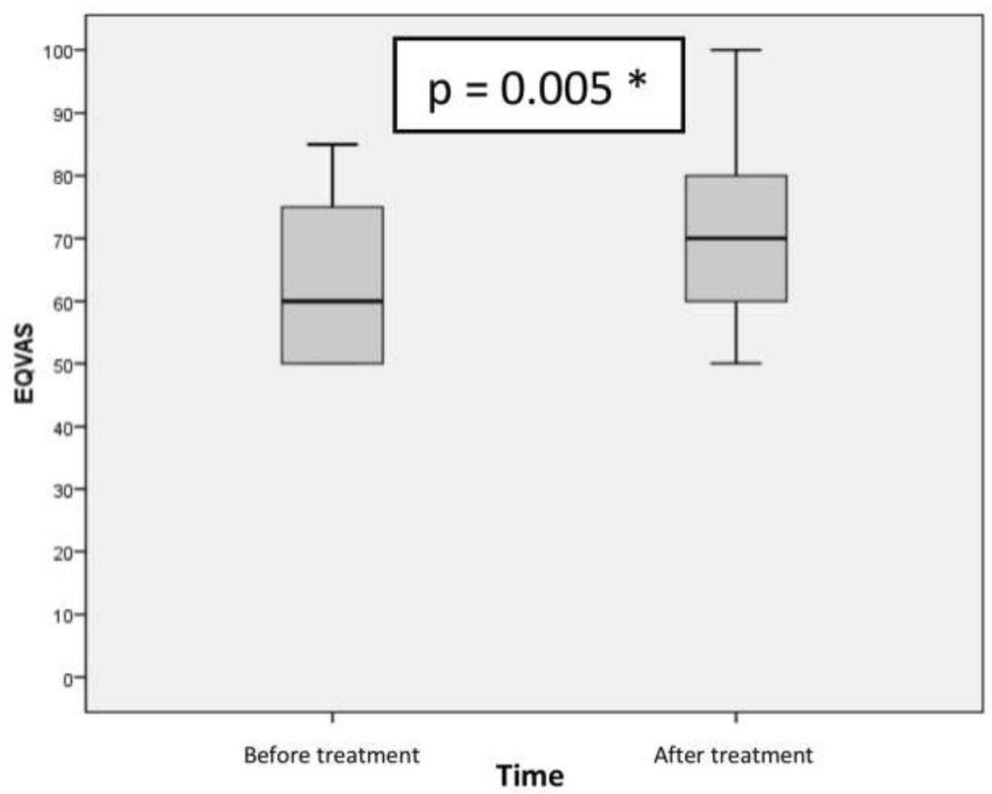

Fig. 3 The mean of EQVAS score before and after 12 weeks of oral sildenafil therapy $3 \times 20 \mathrm{mg}$ in adult patients with PAH due to uncorrected secundum ASD proved to be statistically significant. * $p<0.05 ; 95 \% \mathrm{Cl}$ 
Table 2 EQ5D utility score and EQ-VAS score analysis

\begin{tabular}{|c|c|c|c|c|c|}
\hline \multirow[t]{2}{*}{ Time } & \multicolumn{5}{|c|}{ EQ5D Utility Score } \\
\hline & Median & Minimum & Maximum & Z-score & $p$ \\
\hline Before treatment & 0.604 & 0.098 & 0.766 & -2.703 & $0.007^{*}$ \\
\hline After treatment & 0.664 & 0.393 & 0.798 & & \\
\hline \multirow[t]{3}{*}{ Time } & \multicolumn{5}{|c|}{ EQ-VAS Score } \\
\hline & Mean (SD) & Difference (SD) & \multicolumn{2}{|c|}{ Mean 95\% Cl } & $p$ \\
\hline & & & Lower & Upper & \\
\hline Before treatment & $65 \pm 13.06$ & $6.67 \pm 8.75$ & 2.32 & 11.02 & $0.005^{*}$ \\
\hline After treatment & $71.67 \pm 15.53$ & & & & \\
\hline
\end{tabular}

SD standard deviation, EQ5D EuroQoL-5 Dimensions, EQVAS EuroQoL-Visual Analogue Scale, ${ }^{*} p<0.05 ; 95 \% \mathrm{Cl}$

dimension. Severe problems experienced by $11 \%$ of subjects on both pain/discomfort and anxiety/depression dimensions, while $6 \%$ of the subjects felt severe problems on performing usual activities. This result is in accordance with the study by Thompson et al. (2001) in Germany who found that the best performance of both primary and secondary PAH patients was experienced in the self-care dimension while the worst performance was reported on the dimension of usual activities. In this study, $20 \%$ of subjects experienced severe problems while performing usual activities and less than $10 \%$ experienced severe problems in other dimensions [21]. Mychaskiw et al. (2010) who examined the health status of PAH patients in the subjects of SUPER 1 clinical trial found that moderate to severe problems mostly occur in the usual activity dimension (77\%), while the least occur in self-care dimension (24\%) [22].

After 12 weeks of treatment, severe-problem response level was no longer experienced in the dimensions of pain/discomfort, anxiety/depression, and usual activities. The percentage of subjects who did not had any complain in all of the 5 EQ-5D dimensions were increased. The

Table 3 Factor affecting EQ-5D utility score and EQ-VAS score difference

\begin{tabular}{|c|c|c|c|c|}
\hline Variable & Utility Score Difference & $P$ & EQ-VAS Score Difference & $P$ \\
\hline \multicolumn{5}{|l|}{ Gender } \\
\hline Male, $n=3$ & $0.011 \pm 0.018$ & 0.083 & $11.67 \pm 7.64$ & 0.242 \\
\hline Female, $n=15$ & $0.001 \pm 0.109$ & & $16.67 \pm 5.77$ & \\
\hline \multicolumn{5}{|l|}{ Age } \\
\hline$<38$ y.o, $n=9$ & $0.089 \pm 0.114$ & 0.656 & $4.44 \pm 9.17$ & 0.119 \\
\hline$\geq 38$ y.o, $n=9$ & $0.122 \pm 0.210$ & & $10 \pm 7.50$ & \\
\hline \multicolumn{5}{|l|}{ Education status } \\
\hline Low, $n=2$ & $0.254 \pm 0.530$ & 1.000 & $15 \pm 7.10$ & 0.166 \\
\hline High, $n=16$ & $0.062 \pm 0.042$ & & $6.25 \pm 8.47$ & \\
\hline \multicolumn{5}{|l|}{ Marital Status } \\
\hline Married, $n=15$ & $0.052 \pm 0.034$ & 0.339 & $13.33 \pm 11.55$ & 0.460 \\
\hline Not Married, $n=3$ & $0.185 \pm 0.160$ & & $5 \pm 13.23$ & \\
\hline \multicolumn{5}{|l|}{ Occupation } \\
\hline Employed, $n=5$ & $0.027 \pm 0.045$ & 0.091 & $9 \pm 7.42$ & 0.443 \\
\hline Unemployed, $n=13$ & $0.494 \pm 0.460$ & & $4 \pm 8.9$ & \\
\hline \multicolumn{5}{|l|}{ Other treatment } \\
\hline With treatment, $n=8$ & $0.192 \pm 0.208$ & 0.089 & $5 \pm 9.64$ & 0.249 \\
\hline No treatment, $n=10$ & $0.051 \pm 0.050$ & & $8.13 \pm 8.43$ & \\
\hline \multicolumn{5}{|l|}{ Comorbid disease } \\
\hline With comorbid disease, $n=2$ & $0.099 \pm 0.140$ & 0.944 & $2.5 \pm 3.54$ & 0.511 \\
\hline Without comorbid disease, $n=16$ & $0.106 \pm 0.171$ & & $10 \pm 14.14$ & \\
\hline
\end{tabular}

Description: Mann Whitney test analysis results showed $p$ value $>0.05$ in all sub groups. This means that there is no statistically significant difference between the factors affecting HRQoL to the difference of EQ-5D utility score and EQ-VAS score, ${ }^{*} p<0.05$ 
severity of each EQ-5D dimension problem were decreased. In line with these results, Pepke-Zaba et al. (2008) proved in his study that improvement was achieved in all dimensions of EQ-5D after 12 weeks of sildenafil therapy [8].

A clinical trial by Pepke-Zaba et al. (2008) found that the mean of EQ-5D utility score changed $0.10 \pm 0.04(p<$ $0.01)$ and the mean of EQ-VAS changed $8 \pm 2(p<0.01)$ [8]. Our study showed similar changes that after sildenafil therapy, the median of EQ-5D utility score was increased after therapy (before $=0.604$, after $=0.664 ; Z=-2.703$, p: $0,007)$, while the mean of EQ-VAS score also were increased $6.67 \pm 8.75$ (95\% CI, 2.32 to 11.02$) p$-value 0.005 .

Determination of drug effects on HRQoL is an important component in evaluating the effect of drugs on clinical outcomes and health care. Several previous studies that evaluated HRQoL after sildenafil administration showed consistent results with this study. A study in patients with primary pulmonary hypertension $(n=22)$ conducted by Sastry et al. (2004) mentioned that there was an increase in dyspnea and fatigue components of heart failure questionnaire after receiving 12 weeks sildenafil therapy (dose: $3 \times 25 \mathrm{mg}, 3 \times 50 \mathrm{mg}$ and $3 \times 100$ $\mathrm{mg}$ ) [23]. Another study by Wong et al. (2007), involving 19 HAP patients (idiopathic, connective tissue disease, and CHD, also evaluated HRQoL changes 3 months after sildenafil therapy (dose: $3 \times 25 \mathrm{mg}$ and $3 \times 50 \mathrm{mg}$ ) using SF-36 questionnaire. There was an increase on physical, social, and general health score [24]. Tay et al. (2011) used CAMPHOR questionnaire to evaluate HRQoL in 12 patients with Eisenmenger syndrome who were given sildenafil $3 \times 20 \mathrm{mg}$. The result showed an improvement in HRQoL after 3 months of therapy [25].

Although the drug administration significantly improves the EQ-5D based on statistics, the clinical benefit can be trivial for patients. Thus, the score difference must exceed the MCID (Minimal Clinical Important Difference) that represent the minimal amount of benefit that were recognized by the patient [26]. A review of 18 studies conducted by Coretti et al. (2014) stated that MCID for EQ-5D index ranged from 0.03 to 0.52 [26]. The EQ-5D median difference from this study is 0.06 which concluded that sildenafil therapy gave a clinically significant benefit for the patients. However, none of the 18 studies used in the review were conducted in patients with cardiac problem. To the best of our knowledge, there are no studies assessing MCID for EQ-5D index in cardiac problem patient population. Other than that, we believe that the result can be used as a treatment consideration for pulmonary arterial hypertension cases especially in developing countries.

Demographic factors such as age, sex, marital status, education level, and employment status have an influence on HRQoL. A systematic review by Gu et al. (2016) who assessed factors affecting HRQoL of PAH patients explained that HRQoL is influenced by demographic characteristics (such as living alone, decreased social support), mental health (such as anxiety, depression, stress), physical health (such as exercise and symptomatic capacity), and pharmacologic therapy [4]. In this study, the utility score mean of subjects aged $<38$ years was lower than subjects aged $\geq 38$ years, but the mean of EQ-VAS score was the opposite $(p>0.05)$. Study by Matura et al. (2014) that examined the difference in symptoms severity and HRQoL of young, middle, and older PAH patients concluded that the decrease in HRQoL component was experienced by all age groups, but the younger age group had slightly better physical function compared to other groups [27]. Symptom severity, therapy complexity, or psychological stressors made the patients hard to work. This led to job losses, disrupted economic conditions and social isolation [28].

Nilsson (2012) mentioned that in a group of unmarried / single patients had a low HRQoL [29]. Similarly, this study found that the mean of both utility scores and EQ-VAS of unmarried subjects were lower than those married subjects $(p>0.05)$. Living alone and minimal social support worsen HRQoL emotional dimension score. In contrast, working actively is associated with a better HRQoL physical dimension score [4]. The mean of both utility scores and EQ-VAS in unemployed subgroup in this study, were lower than those that worked $(p>0.05)$.

Delcroix and Howard (2015) published an article review on the burden of PAH disease and its impact on quality of life. It was explained that PAH patients who aged $>50$ years old were reported to have more comorbid diseases such as ischemic heart disease, coronary artery disease, hypertension, atrial fibrillation, diabetes, and hypothyroidism than younger patients. The presence of comorbidities results in delayed diagnosis of PAH in older patients. The higher burden of comorbidities also contributes to the lower survival rates of older PAH patients in the UK and Ireland, which is about 3 times higher than the younger population ( $\leq 50$ years) [30]. In line with this, in this study, the mean of EQ-5D utility score and EQ-VAS of subjects with comorbidities were lower than those without comorbidities $(p>0.05)$.

Supportive therapies (such as diuretics, digoxin, oral anticoagulants, or oxygen) is one of the PAH patient's management strategies mentioned in the ESC guidelines on PAH (2015). Right heart failure leads to fluid retention, increased central venous pressure, hepatic congestion, ascites, and peripheral edema. Clinical experience shows the benefits of diuretics to reduce fluid retention symptoms, but no randomized trials related to diuretic use in $\mathrm{PAH}$ patients. Diuretic therapy is recommended in PAH patients with signs of right heart failure and fluid retention, with recommendation class Ic. Aldosterone antagonist 
therapy may be considered, along with plasma electrolyte levels and renal function monitoring, to prevent hypokalemia and pre-renal kidney disease [31].

High prevalence of vascular thrombotic lesions was found on postmortem examination of idiopathic $\mathrm{PAH}$ patients. In addition, the abnormalities of the coagulation and fibrinolysis cascades in the $\mathrm{PAH}$ patient population have also been reported. Oral anticoagulants are administered to PAH patients with consideration of increased risk of venous thromboembolism (heart failure and immobilization). The benefits of oral anticoagulant therapy are limited to idiopathic PAH, hereditary PAH, and anorexigen-related PAH (recommendation class IIb). This is largely derived from retrospective single center studies. In a contrary, the research result conducted from registry and randomized clinical trials are heterogenous and inconclusive [31]. Current evidence of anticoagulant drugs' efficacy and safety in PAH patient populations is limited. The clinical guidelines do not recommend routine anticoagulant treatment in Eisenmenger syndrome patients and suggest to give anticoagulant treatment in atrial fibrillation and pulmonary artery thrombosis without major haemorrhage [32].

In this study $44,44 \%$ (8) subjects received other therapy, including PAH support therapy. A subject (5.56\%) was treated with oral furosemide if necessary, six (33.34\%) subjects treated with oral furosemide $1 \times 20 \mathrm{mg}$ and oral digoxin $1 \times 0.125 \mathrm{mg}$, and a subject (5.56\%) with accompanying atrial fibrillation received oral furosemide $1 \times 40 \mathrm{mg}$, digoxin $1 \times 0,125 \mathrm{mg}$, spironolactone $1 \times 25$ $\mathrm{mg}$, and warfarin $1 \times 2 \mathrm{mg}$. The mean of EQ-5D utility score and EQ-VAS in group of subjects receiving other therapies were lower than without comorbidities $(p>$ $0.05)$. This is in line with cross-sectional studies by Zlupko et al (2008) that evaluate HRQoL PAH patients with various etiologies such as idiopathic, familial, systemic sclerosis, CHD, human immunodeficiency virus (HIV), liver disease, anorexigen, and obstructive pulmonary venous disease. A total of 93 subjects who were recruited received epoprostenol therapy (28\%), bosentan (49\%), calcium channel blockers (47\%), sildenafil (3\%), digoxin (33\%), diuretics (57\%) and warfarin (49\%). The HRQoL evaluation was measured by a specific PAH disease questionnaire MLHF-PH. The study found a severe HRQoL disorder in all subjects. There were no HRQoL differences in patients treated with diuretics, digoxin, and oxygen [33].

\section{Conclusion}

This study concluded that oral sildenafil therapy $20 \mathrm{mg}$ three times per day for 12 weeks in PAH patients due to uncorrected secundum ASD significantly improve HRQoL.

\section{Abbreviations}

ASD: Atrial Septal Defect; CAMPHOR: Cambridge Pulmonary Hypertension Outcome Review; Cl: Confidence Interval; CHD: Congenital Heart Disease; DIG: Digitalis Investigation Group; EQ-5D-3L: EuroQoL-5 Dimensions-3 Levels; HIV: Human Immunodeficiency Virus; HRQoL: Health-Related Quality of Life; MLHFQ: Minnesota Living with Heart Failure Questionnaire; NYHA FC: New York Heart Association Functional Class; PAHSS: Pulmonary Arterial Hypertension Symptom Scale; PRO: Patient-Reported Outcome; VAS: Visual Analog Scale; WHO: World Health Organization

\section{Acknowledgements \\ The authors wish to thank the patients and their caregivers who provided their time to participate in the study.}

\section{Authors' contributions}

$\mathrm{FH}, \mathrm{PPRG}$, and LKD participated in concepting and designing the study. FH participated in the collecting of data. PPRG and LKD participated in the analysis and interpretation of data. FH wrote the draft of the manuscript. All authors critically revised the manuscript and approved the final version to be published.

\section{Authors' information}

Not Applicable.

Funding

The authors received no specific funding for this research.

\section{Availability of data and materials}

Data can be shared upon contact with the correspondence author.

\section{Ethics approval and consent to participate}

Patients provided written informed consent to participate in the study. This study was ethically approved by the ethical commission of biomedical research Faculty of Medicine, Universitas Gadjah Mada, Yogyakarta and permission from the Director of Dr. Sardjito General Hospital Yogyakarta. Patients provided written informed consent to participate in the study.

Consent for publication

Not applicable.

Competing interests

The authors declare that they have no competing interests.

Received: 23 January 2020 Accepted: 16 July 2020

Published online: 14 August 2020

\section{References}

1. D'Alto M, Mahadevan VS. Pulmonary arterial hypertension associated with congenital heart disease. Eur Respir Rev. 2012;21(126):328-37.

2. Dinarti LK. Hubungan antara kadar prostasiklin, nitrogen monoksida, endotelin-1 dengan hipertensi arteri pulmonal pada pasien defek septum atrium dewasa yang belum dikoreksi. In: Disertasi. Program Doktor IImu Kedokteran dan Kesehatan FK UGM; 2017.

3. Post MC. Association between pulmonary hypertension and an atrial septal defect. Neth Hear J. 2013;21:331-2.

4. Gu S, Hu H, Dong H. Systematic review of health-related quality of life in patients with pulmonary arterial hypertension. PharmacoEconomics. Switzerland: Springer International Publishing; 2016.

5. Cícero C, Franchi SM, Barreto AC, Lopes AAB. Lack of tight association between quality of life and exercise capacity in pulmonary arterial hypertension. Arq Bras Cardiol. 2012;99(4):876-85.

6. Mathai SC, Suber T, Khair RM, Kolb TM, Damico RL, Hassoun PM. Healthrelated quality of life and survival in pulmonary arterial hypertension. Ann Am Thorac Soc. 2015;13:1-31.

7. Wang R, Jiang F, Zheng Q, Li C, Peng X, He C, et al. Efficacy and safety of sildenafil treatment in pulmonary arterial hypertension. Respir Med. 2014; 108:531e537.

8. Pepke-Zaba J, Gilbert C, Collings L, MCJ B. Sildenafil improves health-related quality of life in patients with pulmonary arterial hypertension. CHEST. 2008; 133:183-9. 
9. Barst RJ, Langleben D, Frost A, Horn EM, Oudiz R, Shapiro S, et al. Sitaxsentan therapy for pulmonary arterial hypertension. Am J Respir Crit Care Med. 2004;169(4):441-7.

10. Girgis RE, Frost AE, Hill NS, Horn EM, Langleben D, McLaughlin W, et al. Selective endothelin a receptor antagonism with Sitaxsentan for pulmonary arterial hypertension associated with connective tissue disease. Ann Rheum Dis. 2007;66(11):1467-72.

11. Keogh AM, McNeil KD, Wlodarczyk J, Gabbay E, Williams TJ. Quality of life in pulmonary arterial hypertension: improvement and maintenance with Bosentan. J Heart Lung Transplant. 2007;26(2):181-7.

12. Bonner N, Abetz L, Meunier J, Sikirica M, Mathai SC. Development and validation of the living with pulmonary hypertension questionnaire in pulmonary hypertension patients. Health Qual Life Outcomes. 2013;11:161.

13. Reenen MV, Oppe M. EQ-5D-3L user guide basic information on how to use the EQ-5D-3L instrument. EuroQol Res Found. 2015;1:1-20.

14. Sari A, Lestari ND, Perwitasari DA. Validasi St European Quality of Life-5 Dimensions (EQ-5D) Versi Indonesia pada Pasien Hipertensi di Puskesmas Kotagede II Yogyakarta. Pharmaciana. 2015;5(2):131-8.

15. Phillips C, Thompson G. What is a QALY? Hayward Medl Commun. 2001;1:1-5.

16. Yusof FA, Goh A, Azmi S. Estimating an EQ-5D value set for Malaysia using TTO and VAS methods. Value Health. 2012;15(1):85-90.

17. Endarti D, Riewpaiboon A, Thavorncharoensap M, Praditsitthikorn N, Hutubessy R, Kristina SA. A comparison of EQ-5D-3L index scores using foreign value sets for Indonesian sample with cervical cancer. Value Health. 2016;19:A807-918.

18. Haque S, Khan LR, Mahmud RS. Faruq, Chowdury a.W., Ali M.S. pulmonary artery pressure profile in atrial septal defect patients. Bangladesh Heart J. 2016:30(1):27-8.

19. Vogel M, Berger F, Kramer A, Alexi-Meshkishvili V, Lange PE. Incidence of secondary pulmonary hypertension in adults with atrial septal or sinus venosus defects. Heart. 1999;82:30-3.

20. Engelfriet PM, Duffels MGJ, Moller T, Boersma E, Tijssen JGP, Thaulow E, et al. Pulmonary arterial hypertension in adults born with a heart septal defect: the euro heart survey on adult congenital heart disease. Heart. 2007;93:682-7.

21. Thompson S, Fichte K, Miltenburger C, Nikkho S, Higenbottam T, Olschewski $\mathrm{H}$, Seeger W. Measuring health-related quality of life with the EuroQoL EQ5D instrument in clinical trials of new treatments for pulmonary hypertension. In: 17th Plenary Meeting of the EuroQoL Group, Pampiona, 2829 September 2000. Discussion paper. Spain: Universad Publica de Navarra; 2001. p. 239-48

22. Mychaskiw M.A., Berger A., Mardekian J., Hwang L.J., Oster G. Methods for Estimating Health-State Utilities in Pulmonary Arterial Hypertension. Value Health. 2010;13(7):A239-501.

23. Sastry BKS, Narasimhan C, Reddy NK, Raju BS. Clinical efficacy of sildenafil in primary pulmonary hypertension. J Am Coll Cardiol. 2004;43:7.

24. Wong RCC, Koh GM, Choong PH, Yip WLJ. Oral sildenafil therapy improves health-related quality of life and functional status in pulmonary arterial hypertension. Int J Cardiol. 2007;119:400-2.

25. Tay ELW, Papaphylactou M, Diller GP, Alonso-Gonzalez R, Inuzuka R, Giannakoulas G, et al. Quality of life and functional capacity can be improved in patients with Eisenmenger syndrome with oral sildenafil therapy. Int J Cardiol. 2011;149:372-6.

26. Coretti S, Ruggeri M, Mcnamee P. The minimum clinically important difference for EQ-5D index: a critical review. Expert Rev Pharmacoecon Outcomes Res. 2014;14(2):221-33. https://doi.org/10.1586/14737167.2014. 894462

27. Matura LA, McDonough A, Carroll DL. Symptom prevalence, symptom severity, and health-related quality of life among young, middle, and older adults with pulmonary arterial hypertension. Am J Hosp Palliat Care. 2014; 33(3):214 http://ajh.sagepub.com/content/early/2014/10/01/1049909114554 079 .

28. Tyrka A, Sarnecka A, Jonas K, Waligora M, Kopec G, Podolec P. Healthrelated quality of life in pulmonary arterial hypertension (RCD code: II). J Rare Cardiovasc Dis. 2014;2(1):5-8.

29. Nilsson E. Aspects of health-related quality of life. Associations with psychosocial and biological factors, and use as patient-reported outcome in routine health care. Sweden: Linköping University Medical Dissertations No. 1295; 2012.

30. Delcroix M, Howard L. Pulmonary arterial hypertension: the burden of disease and impact on quality of life. Eur Respir Rev. 2015;24:621-9.
31. Galiè N, Hoeper MM, Humbert M, Vachiery JL, Gibbs S, Lang I, et al. Guidelines for the diagnosis and treatment of pulmonary hypertension: the task force for the diagnosis and treatment of pulmonary hypertension of the European Society of Cardiology (ESC) and the European Respiratory Society (ERS), endorsed by the International Society of Heart and Lung Transplantation (ISHLT). Eur Heart J. 2015;1:5-47.

32. van Dissel AC, Mulder BJ, Bouma BJ. The changing landscape of pulmonary arterial hypertension in the adult with congenital heart disease. J Clin Med. 2017;6(40):1-22.

33. Zlupko M, Harhay MO, Gallop R, Shin J, Archer-Chicko C, Patel R, et al. Evaluation of disease-specific health-related quality of life in patients with pulmonary arterial hypertension. Respir Med. 2008;102:1431-8.

\section{Publisher's Note}

Springer Nature remains neutral with regard to jurisdictional claims in published maps and institutional affiliations.
Ready to submit your research? Choose BMC and benefit from:

- fast, convenient online submission

- thorough peer review by experienced researchers in your field

- rapid publication on acceptance

- support for research data, including large and complex data types

- gold Open Access which fosters wider collaboration and increased citations

- maximum visibility for your research: over $100 \mathrm{M}$ website views per year

At BMC, research is always in progress.

Learn more biomedcentral.com/submissions 